\title{
Multi-year spatial distribution of Antarctic sea ice (1988 - 2017)
}

\author{
Xingdong Wang ${ }^{1,2,3}$, Shuhui Yang ${ }^{1, *}$, and Zhankai $\mathrm{Wu}^{1}$ \\ ${ }^{1}$ Key Laboratory of Grain Information Processing and Control (Henan University of Technology), Ministry of Education, \\ Zhengzhou, China \\ ${ }^{2}$ College of Information Science and Engineering, Henan University of Technology, Zhengzhou, China \\ ${ }^{3}$ National-Local Joint Engineering Laboratory on Digital Preservation and Innovative Technologies for the Culture of \\ Traditional Villages and Towns, Hengyang, China
}

\section{Article history:}

Received 8 September 2019

Revised 15 November 2020

Accepted 16 November 2020

\section{Keywords:}

Antarctica, Remote sensing, Sea ice concentration, Spatial change, Multiyear ice

\section{Citation:}

Wang, X., S. Yang, and Z. Wu, 2021: Multi-year spatial distribution of Antarctic sea ice (1988 - 2017). Terr. Atmos. Ocean. Sci., 32, 229-240, doi: 10.3319/TAO.2020.11.16.01

\begin{abstract}
In this study, we used daily sea-ice concentration data from the National Snow and Ice Data Center from 1988 to 2017 to investigate the spatial distribution of Antarctic sea ice by calculating the annual mean sea-ice concentration and multi-year sea ice in five sub-regions of Antarctica. Variations in these parameters were analyzed for three individual 10-year increments (1988 - 1997, 1998 - 2007, and 2008 - 2017) as well as for the entire 30-year period, and spatial comparisons of both were made for the sub-regions. Results showed that the mean sea-ice concentration for the entire Antarctic region over the 30-year period was 0.506. From 2008 to 2017, the sea-ice concentration decreased at a rate of $-0.28 \% \mathrm{yr}^{-1}$. The Weddell Sea was found to have the largest area of multi-year sea ice, whereas the Indian Ocean and the Pacific Ocean had the least. Spatially, the multi-year sea ice area increased mainly in the Weddell Sea, whereas the Bellingshausen Sea, Amundsen Sea, and Ross Sea experienced decreasing sea ice areas. In conclusion, regional differences in the spatial distribution of the Antarctic sea ice were observed. The temporal trend and range of the sea-ice concentration differed between the five sub-regions, as did the spatial distribution and temporal trend of multi-year sea ice.
\end{abstract}

\section{INTRODUCTION}

The Antarctic region reflects general changes in global sea ice; therefore, any changes in ice found on the continent are a main issue of concern to the international community (Comiso 2000; Cook et al. 2005; Screen et al. 2018). As one of the main sources of cold air on Earth, Antarctica has a profound impact on global climate (Massom and Stammerjohn 2010). Sea ice is one of the most important environmental factors in Antarctica, and changes in sea ice play an important role in regulating the global climate. The area covered by Antarctic sea ice accounts for approximately $5.3 \%$ of the global ocean area and is generally distributed along the periphery of the Antarctic continent.

Passive microwave remote sensing technology is scarcely affected by weather, and the sea-ice concentration data can be directly obtained from the passive microwave sensor. Therefore, this approach has become the main means

\footnotetext{
* Corresponding author

E-mail:ysh1563852@163.com
}

of monitoring the sea ice area (SIA). Parkinson (2004) found that the sea ice extent (SIE) in the Antarctic during 1979 1998 increased by $11180 \pm 4190 \mathrm{~km}^{2} \mathrm{yr}^{-1}$. Cavalieri and Parkinson (2008) showed that the Antarctic SIE increased by $1.0 \pm 0.4 \% \mathrm{yr}^{-1}$ from 1979 to 2006 . The Antarctic SIE and sea surface temperature propagate from west to east on an El Niño timescale (Simmonds and Jacka 1995; White et al. 2004; White and Simmonds 2006). Cavalieri et al. (2003) determined that the Antarctic SIE decreased significantly from 1973 to 1977 before gradually increasing again from 1977 to 2002. Between 1979 and 2013, the annual mean total Antarctic SIE increased at a rate of $195 \times 10^{3} \mathrm{~km}^{2} \mathrm{dec}^{-1}$ $\left(1.6 \% \mathrm{dec}^{-1}\right)$ (Simmonds 2015). The largest regional positive trend in annual mean SIE has been reported to be $119 \times 10^{3}$ $\mathrm{km}^{2} \mathrm{dec}^{-1}\left(4.0 \% \mathrm{dec}^{-1}\right)$ in the Ross Sea (RS) sector for the period 1979 - 2013 (Turner et al. 2016). Trends in satellitederived Antarctic sea-ice concentrations (1979 - 2002) exhibited a pronounced increase (decrease) \pm of $4-10 \% \mathrm{dec}^{-1}$ in the central Pacific sector (Bellingshausen/western Weddell sector) (Liu et al. 2004). Zwally et al. (2002) reported 
that from 1979 to 1996, the total Antarctic SIE and SIA increased by $11180 \pm 4190 \mathrm{~km}^{2} \mathrm{yr}^{-1}$ and $10860 \pm 3720 \mathrm{~km}^{2} \mathrm{yr}^{-1}$, respectively. Regionally, trends were positive in the Pacific Ocean (PO), RS, and Weddell Sea (WS), and negative in the Indian Ocean (IO), Bellingshausen Sea, and Amundsen Sea. From 2002 to 2011, the Antarctic SIE and SIA increased by 3.64 and $3.8 \%$, respectively (Shen et al. 2017).

Thus far, studies on the Antarctic sea ice have primarily focused on the SIE and SIA. The existing research pertaining to the spatial distribution of sea ice, based on the annual average sea-ice concentrations and multi-year ice, is inadequate; further, the length of the investigation periods considered is also insufficient. In the present study, the spatial distribution of Antarctic sea ice between 1988 and 2017 was investigated using two sea-ice parameters: seaice concentration and multi-year ice. Analysis of the spatial distribution of the sea-ice concentration can provide a clear indication of the distribution patterns of sea-ice, which are essentially the 'root-causes' and more useful than solely considering SIA changes. Multi-year ice is maintained on a relatively stable basis; hence, such data can more accurately reflect the spatial distribution of sea ice and variations in spatial changes. The variation in Antarctic sea ice differs from that of the sea ice at the Antarctic continental margin. Therefore, it is important to study the changes in the seas of the Antarctic continental margin to deepen our understanding of the overall variations in the Antarctic sea ice change.

\section{DATASET AND METHODS}

The data used in this study were derived from the National Snow and Ice Data Center (NSIDC). The data provide daily and monthly mean sea-ice concentration images for Antarctica from November 1978 to the present. The daily data were used here. Images were obtained via polar stereographic projection, which covers the region from $50^{\circ} \mathrm{S}$ to the south pole, with a $25 \mathrm{~km}_{\text {pixel }}{ }^{-1}$ resolution grid (Maslan$\mathrm{ik}$ and Stroeve 2016). The data were sourced using satellite microwave radiation, including a scanning multichannel microwave radiometer (SMMR) on the Nimbus-7 satellite, the special sensor microwave imagers (SSM/I) on F8, F11, and F13 of the Defense Meteorological Satellite Program (DMSP), and the special sensor microwave imager sounder (SSMIS) on F17 and F18 (Cavalieri and Parkinson 2012).

The sea-ice concentration was calculated using the NASA Team algorithm proposed by the Sea Ice Division of NASA's Goddard Space Flight Center Hydrological Sciences Laboratory (Swift and Cavalieri 1985). The NSIDC's daily sea-ice concentrations were used to calculate the SIE. We only used NSIDC's data from 1988 to 2017 because not all data for the period from 1979 to 1987 are as available in the form of daily concentrations, and there are also instances of missing data. The daily data were further used to calculate mean annual concentrations.
The multi-year SIA and SIE were determined using the daily mean sea-ice concentratins provided by the NSIDC. The daily SIE data were pre-processed prior to the calculation of the multi-year SIA. Firstly, the daily mean total SIE was calculated and the results for each day in each year were obtained. Generally, multi-year ice refers to the sea ice that still exists after melting for at least one summer. In the present study also, we considered the sea ice existing after the melting season as the multi-year ice of that year (Lange et al. 2019; Bi et al. 2020). Hence, by determining the minimum sea-ice range for each year from 1987 to 2017, the annual average ice distribution during 1988 - 2017 was obtained. The multi-year ice for the entire 30-year period was then calculated. In the sea-ice concentration images, if a pixel showed the presence of the multi-year ice for only two years, the ice age was defined as two years. Similarly, if a pixel showed the presence of the multi-year ice for 30 years, the ice age was defined as 30 years.

\section{RESULTS AND ANALYSIS}

\subsection{Spatial Distribution of the Sea-Ice Concentration Between 1988 and 2017}

By referring to previous studies on Antarctic sea ice (Zwally et al. 2002; Parkinson and Cavalieri 2012), we divided the entire Antarctic region into five sub-regions: the IO $\left(20\right.$ - $\left.90^{\circ} \mathrm{E}\right), \mathrm{PO}\left(90-160^{\circ} \mathrm{E}\right), \mathrm{RS}\left(160^{\circ} \mathrm{E}-130^{\circ} \mathrm{W}\right)$, Bellingshausen Sea and Amundsen Sea (collectively BS) (130 $\left.-60^{\circ} \mathrm{W}\right)$, and $\mathrm{WS}\left(60^{\circ} \mathrm{W}-20^{\circ} \mathrm{E}\right)$ (Fig. 1). As mentioned, we used the daily mean sea-ice concentration data obtained from the NSIDC for the period from 1988 to 2017. The 30-year mean sea-ice concentration for the entire Antarctic region (0.506) and the spatial distribution amongst the five subregions between 1988 and 2017 were determined (Fig. 2). As can be seen from Fig. 2, the sea ice was mainly distributed in the area south of $55^{\circ} \mathrm{S}$ during this 30 -year period. The 30 -year mean amount and concentration of sea ice differed between the five sub-regions. The sea ice in the $0-180^{\circ} \mathrm{W}$ region covered an obviously greater area than that in the $0-180^{\circ} \mathrm{E}$ region. Sea ice was mainly concentrated in the WS and RS, which accounted for $\sim 68 \%$ of the total area of Antarctic sea ice. Moreover, these sub-regions were largely characterized by a high concentration of sea ice (i.e., $>0.9$ ), with the other high concentration areas being scattered in the marginal waters adjacent to the Antarctic continent.

As a means of obtaining more quantitative results, we divided the sea-ice concentration into eight ranges at intervals of 0.1 . Most studies regard sea ice with a concentration of $<0.15$ to be seawater; hence, we took $0.15-0.3$ as the first concentration range. The SIA is the sum of the grid cell areas multiplied by the sea-ice concentration for all cells with a concentration of at least $15 \%$. The $15 \%$ threshold is used for both SIE and SIA calculations (Parkinson et al. 1999; Heinrichs et al. 2006). The SIA of each concentration range 
was calculated. The results are presented in Table 1 ; it is evident that the largest SIA corresponded to a concentration range of $0.6-0.7$ and accounted for an estimated 20.673\% of the total Antarctic SIA. The SIA that was associated with a concentration range of $0.8-0.9$ covered $0.609 \times 10^{6} \mathrm{~km}^{2}$ ( $6.922 \%$ of the total Antarctic SIA). The smallest SIA corresponded to a concentration range of $0.9-1.0$ and accounted for an estimated $6.826 \%$ of the total Antarctic SIA. Areas with a sea-ice concentration of $>0.9$ were largely distributed in the WS, whereas the sea-ice concentration in the PO was found to be relatively low and the SIA was the lowest.

\subsection{Spatial Variation in Antarctic Sea-Ice Concentration}

\subsubsection{Entire Antarctic Region}

Annual mean sea-ice concentrations were calculated from the daily mean sea-ice concentrations for the entire Antarctic region. The annual mean sea-ice concentration varied relatively little between 1988 and 1997, whereas it varied significantly between 2008 - 2017. Therefore, we selected a 10-year interval to compare the trends and regularity of the spatial distribution of the sea-ice concentration. The spatial variation in the annual mean sea-ice concentration for the entire Antarctic region for three separate 10year intervals (1988 - 1997; 1998 - 2007; 2008 - 2017) was analyzed using linear regression analysis (Fig. 3); regions indicated in black represent a significance level of $\mathrm{p}<0.05$. The green (purple) pixels indicate an increasing (decreasing) rate of change of the mean annual sea-ice concentration during each of the three 10-year intervals. Temporally, trends in sea-ice concentrations for the five sub-regions of Antarctica were significant and different; spatially, the rates of change of the sea-ice concentration for each of the three 10-year intervals were also considerably different (Fig. 3). From 1998 to 2007, a decreasing trend was evident for most of the Antarctic region except for the Amundsen Sea, RS, and parts of the western PO, which exhibited a trend of increasing sea-ice concentration. In addition, the sea-ice concentration in the Amundsen Sea and RS showed a significant downward trend over the 30-year study period.

Liu (2016) studied the spatial rate of change of the sea-ice concentration in Antarctica from 1979 to 2014. The author found that the rate of change of sea-ice density ranged between -1.4 and $1.03 \%$ during this period. Due to the differences between the study period considered by Liu (2016) and that used in this study, different rates of change were determined. However, a common factor in both studies is that they observed considerable regional differences in the variation of sea-ice concentration in Antarctica were observed. The sea-ice concentration in the BS and RS obviously reduced, whereas that in the WS increased.

Table 2 and Fig. 4 present a comparison of temporal and spatial variables of the Antarctic sea-ice concentration over the three separate decade intervals. Between 1988 and 1997, the total Antarctic sea-ice concentration increased by $55.404 \%$, whereas it was $60.848 \%$ between 1998 and 2007, and $34.895 \%$ between 2008 and 2017. During the first two decades, the annual rate of change of the sea-ice concentration increased, but in the latter 10-year interval, a decrease of $-0.283 \% \mathrm{yr}^{-1}$ was observed (Table 2). The change rates of sea-ice concentration in 1988 - 1997, 1998 - 2007, 2008 2017 were significant at $\mathrm{p}<0.01$.

\subsubsection{Sub-Regions}

1988 - 1997: The spatial distribution of the sea-ice concentration in the five sub-regions (Fig. 1) from 1988 to 1997 was analyzed using linear regression. The results are provided in Table 3, whereby the data in the two right-hand columns were plotted as a histogram in Fig. 5. The sea-ice concentration increased at a relatively slow rate of $0.077 \% \mathrm{yr}^{-1}$ over the Antarctic region during this period. The sea-ice concentration increased in all sub-regions except the IO. The western PO sub-region showed the most rapid increase in sea-ice concentration $\left(0.503 \% \mathrm{yr}^{-1}\right)$, and the SIA that showed an increase in the sea-ice concentration accounted for $85.347 \%$ of the total Antarctic SIA. An estimated 51.146\% of the area experienced an increase in sea-ice concentration in the RS, while $48.854 \%$ are experienced a decline; thus the difference between the two was slight. The sea-ice concentration in the BS and WS both exhibited weak growth trends. There was a significant difference between the mean sea-ice concentration and the annual rate of change in the different sub-regions, except for $\mathrm{IO}$, for which the change rate of sea ice concentration was significant at $\mathrm{p}<0.01$.

1998 - 2007: The results of the linear regression of the sea-ice concentration in the five sub-regions from 1998 to 2007 are shown in Table 4 and Fig. 6. The results showed that the sea-ice concentration increased at a relatively slow rate of $0.015 \% \mathrm{yr}^{-1}$ over the entire Antarctic region during this period. An estimated $51.822 \%$ of the sea-ice concentration in the IO increased, while $48.178 \%$ decreased. The sea-ice concentration in the WS increased significantly over time at a rate of $0.536 \% \mathrm{yr}^{-1}$, and $88.632 \%$ of its area showed an increase in the sea-ice concentration. The PO, RS, and BS all exhibited decreasing trends in sea-ice concentration. All of the sub-regions (except for the WS) showed opposite trends to those observed during 1988 - 1997. The changes in the PO between the 10-year intervals were obvious in that the sea-ice concentration presented a clear, increasing trend during 1988 - 1997 but a decreasing trend during 1998 - 2007. The sea-ice concentration in the WS increased more during 1998 - 2007 in comparison to that in the preceding decade. There was a significant difference between the mean sea-ice concentration and the annual rate of change in the five sub-regions. The change rate of sea-ice concentration in IO and WS were significant at $\mathrm{p}<0.01$. 


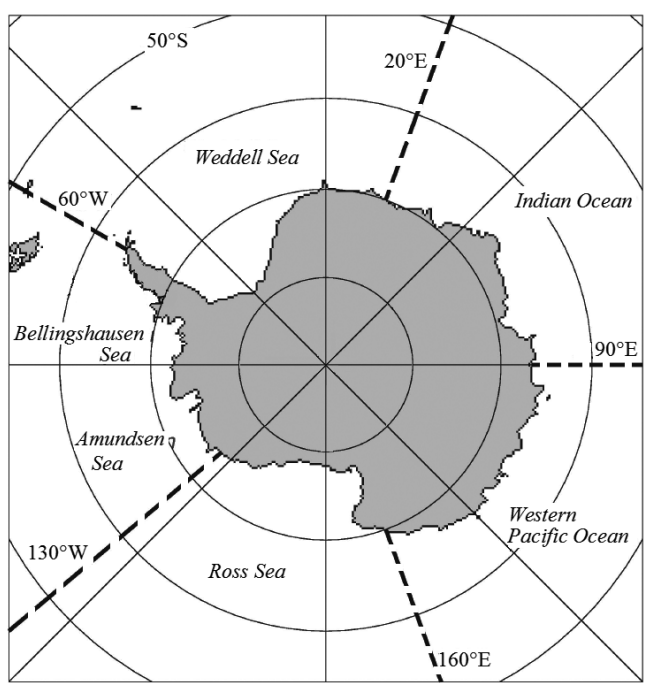

Fig. 1. Distribution of the five sub-regions of Antarctica.

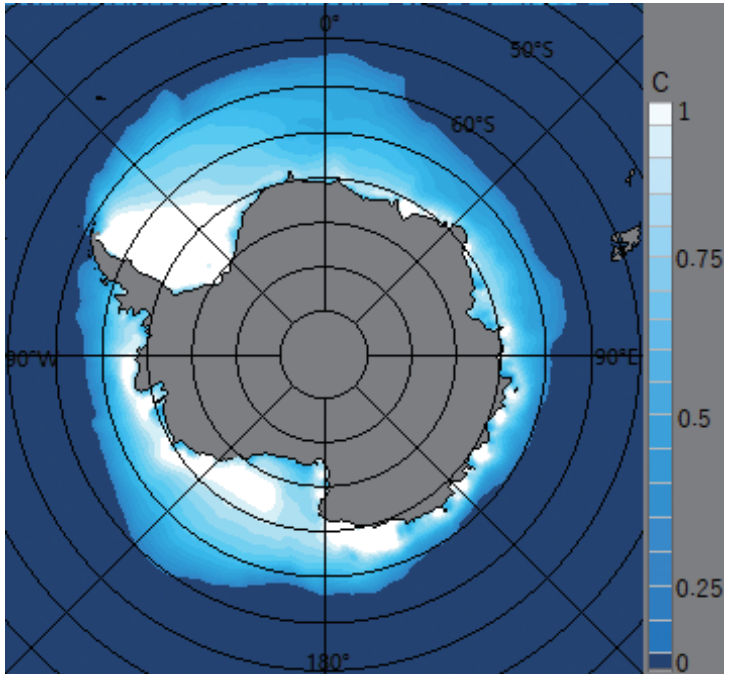

Fig. 2. Mean Antarctic sea-ice concentration for the period from 1988 to 2017 .

Table 1. Sea-ice area (SIA) for different concentration ranges during 1988 - 2017.

\begin{tabular}{c|cccccccc}
\hline Concentration range & $\mathbf{0 . 1 5 - 0 . 3}$ & $\mathbf{0 . 3}-\mathbf{0 . 4}$ & $\mathbf{0 . 4} \mathbf{- 0 . 5}$ & $\mathbf{0 . 5} \mathbf{- 0 . 6}$ & $\mathbf{0 . 6 - 0 . 7}$ & $\mathbf{0 . 7}-\mathbf{0 . 8}$ & $\mathbf{0 . 8}-\mathbf{0 . 9}$ & $\mathbf{0 . 9}-\mathbf{1 . 0}$ \\
\hline Mean concentration & 0.224 & 0.352 & 0.449 & 0.551 & 0.648 & 0.749 & 0.847 & 0.935 \\
SIA $\left(10^{6} \mathrm{~km}^{2}\right)$ & 0.732 & 0.919 & 1.248 & 1.551 & 1.819 & 1.322 & 0.609 & 0.601 \\
Proportion $(\%)$ & 8.318 & 10.451 & 14.174 & 17.615 & 20.673 & 15.021 & 6.922 & 6.826 \\
\hline
\end{tabular}
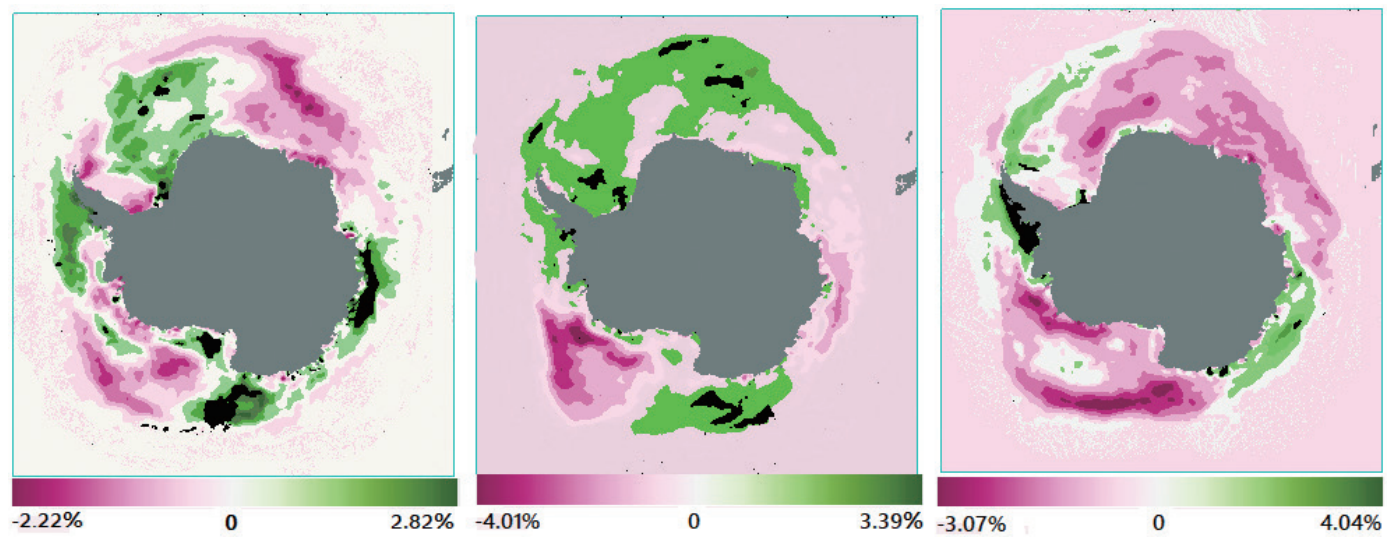

Fig. 3. Spatial distribution of the Antarctic sea-ice concentration rate of change (green: increase; purple: decrease) during three 10-year intervals: 1988 - 1997 (left); 1998 - 2007 (middle); 2008 - 2017 (right), regions indicated in black represent a significance level of $\mathrm{p}<0.05$. 
Table 2. Spatial and temporal variations in the Antarctic sea-ice concentration during the three 10-year intervals.

\begin{tabular}{|c|c|c|c|c|c|c|c|}
\hline & $\begin{array}{c}\text { Mean rate of } \\
\text { change }\left(\% \mathrm{yr}^{-1}\right)\end{array}$ & $\begin{array}{c}\text { Minimum rate of } \\
\text { change }\left(\% \mathbf{y r}^{-1}\right)\end{array}$ & $\begin{array}{c}\text { Maximum rate of } \\
\text { change }\left(\% \mathrm{yr}^{-1}\right)\end{array}$ & $\begin{array}{c}\text { Extent of increase } \\
\left(10^{6} \mathbf{k m}^{2}\right)\end{array}$ & $\begin{array}{c}\text { Extent of decrease } \\
\left(10^{6} \mathbf{k m}^{2}\right)\end{array}$ & $\begin{array}{c}\text { Proportion of } \\
\text { increase }(\%)\end{array}$ & $\begin{array}{l}\text { Proportion of } \\
\text { decrease }(\%)\end{array}$ \\
\hline $1988-1997$ & $0.077 * *$ & -2.219 & 2.818 & 13.797 & 11.106 & 55.404 & 44.596 \\
\hline $1998-2007$ & $0.015^{* *}$ & -4.004 & $3.388^{*}$ & 15.091 & 9.71 & 60.848 & 39.152 \\
\hline $2008-2017$ & $-0.283 * *$ & $-3.069 * *$ & 4.038 & 8.716 & 16.261 & 34.895 & 65.105 \\
\hline
\end{tabular}

Note: $* p<0.05 ; * * p<0.01$.

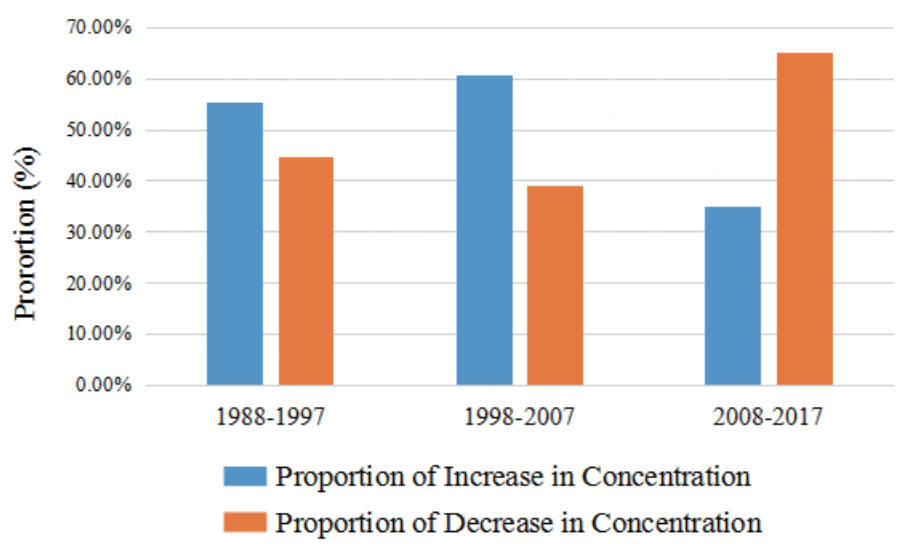

Fig. 4. Comparison of Antarctic sea ice concentration in 1988 - 1997 (left), 1998 - 2007 (middle), and 2008 - 2017 (right).

Table 3. Sea-ice concentration changes in the five Antarctic sub-regions during 1988 - 1997. IO: Indian Ocean; PO: Pacific Ocean; RS: Ross Sea; BS: Bellingshausen Sea and Amundsen Sea; WS: Weddell Sea.

\begin{tabular}{c|cccccc}
\hline & $\begin{array}{c}\text { Mean sea-ice } \\
\text { concentration }\end{array}$ & $\begin{array}{c}\text { Mean rate of } \\
\text { change }\left(\% \mathbf{~ y r}^{-1}\right)\end{array}$ & $\begin{array}{c}\text { Mean rate of } \\
\text { increase }\left(\% \mathbf{~ y r}^{-1}\right)\end{array}$ & $\begin{array}{c}\text { Mean rate of } \\
\text { decrease }\left(\% \mathbf{~ y r}^{-1}\right)\end{array}$ & $\begin{array}{c}\text { Proportion of } \\
\text { increase }(\%)\end{array}$ & $\begin{array}{c}\text { Proportion of } \\
\text { decrease }(\%)\end{array}$ \\
\hline IO & 0.409 & -0.321 & 0.313 & -0.614 & 31.583 & 68.417 \\
PO & 0.469 & $0.503 * *$ & 0.616 & -0.154 & 85.347 & 14.653 \\
RS & 0.547 & $0.032 * *$ & 0.667 & -0.633 & 51.146 & 48.854 \\
BS & 0.505 & $0.225^{* *}$ & 0.706 & -0.469 & 59.089 & 40.911 \\
WS & 0.522 & $0.131^{* *}$ & 0.572 & -0.529 & 59.966 & 40.034 \\
\hline
\end{tabular}

Note: $* p<0.05 ; * *<0.01$.

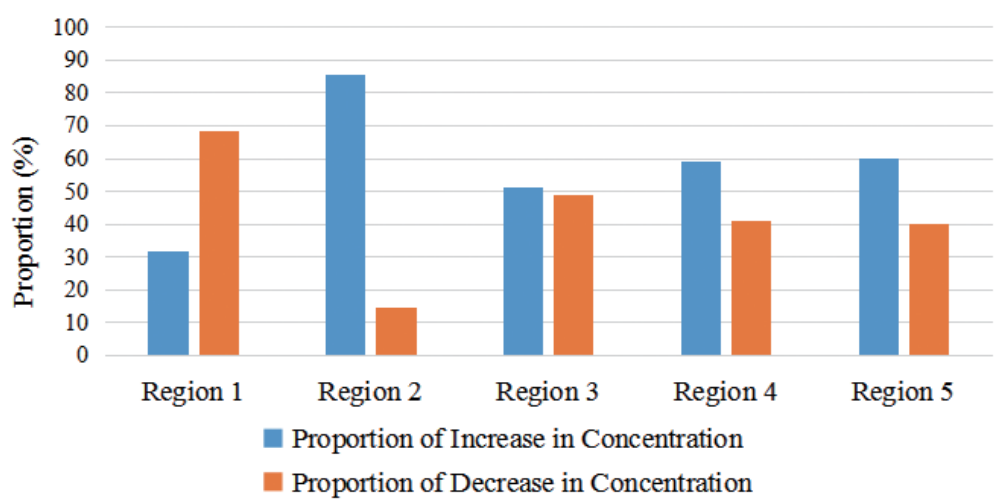

Fig. 5. Statistical results of sea-ice concentration changes in the five Antarctic sub-regions from 1988 to 1997 (blue: proportion of sea ice with an increasing trend of concentration; orange: proportion of sea ice with a decreasing trend of concentration). 
Table 4. Sea-ice concentration changes in the five Antarctic sub-regions during 1998 - 2007. IO: Indian Ocean; PO: Pacific Ocean; RS: Ross Sea; BS: Bellingshausen Sea and Amundsen Sea; WS: Weddell Sea.

\begin{tabular}{ccccccc}
\hline & $\begin{array}{c}\text { Mean sea-ice } \\
\text { concentration }\end{array}$ & $\begin{array}{c}\text { Mean rate of } \\
\text { change }\left(\boldsymbol{\%} \mathbf{y r}^{-1}\right)\end{array}$ & $\begin{array}{c}\text { Mean rate of } \\
\text { increase }\left(\boldsymbol{\%} \mathbf{~ y r}^{-1}\right)\end{array}$ & $\begin{array}{c}\text { Mean rate of } \\
\text { decrease }\left(\boldsymbol{\%} \mathbf{~ y r}^{-1}\right)\end{array}$ & $\begin{array}{c}\text { Proportion of } \\
\text { increase }(\boldsymbol{\%})\end{array}$ & $\begin{array}{c}\text { Proportion of } \\
\text { decrease }(\%)\end{array}$ \\
\hline IO & 0.408 & $0.0289^{* *}$ & 0.398 & -0.368 & 51.822 & 48.178 \\
PO & 0.455 & -0.368 & 0.557 & -0.745 & 29.002 & 70.998 \\
RS & 0.553 & -0.451 & 0.623 & -1.273 & 43.324 & 56.676 \\
BS & 0.512 & -0.398 & 0.406 & -1.207 & 50.191 & 49.809 \\
WS & 0.517 & $0.536^{* *}$ & 0.632 & -0.219 & 88.632 & 11.368 \\
Entire Antarctica & 0.502 & $0.015^{* *}$ & 0.571 & -0.847 & 60.849 & 39.151 \\
\hline
\end{tabular}

Note: $* p<0.05 ; * * p<0.01$.

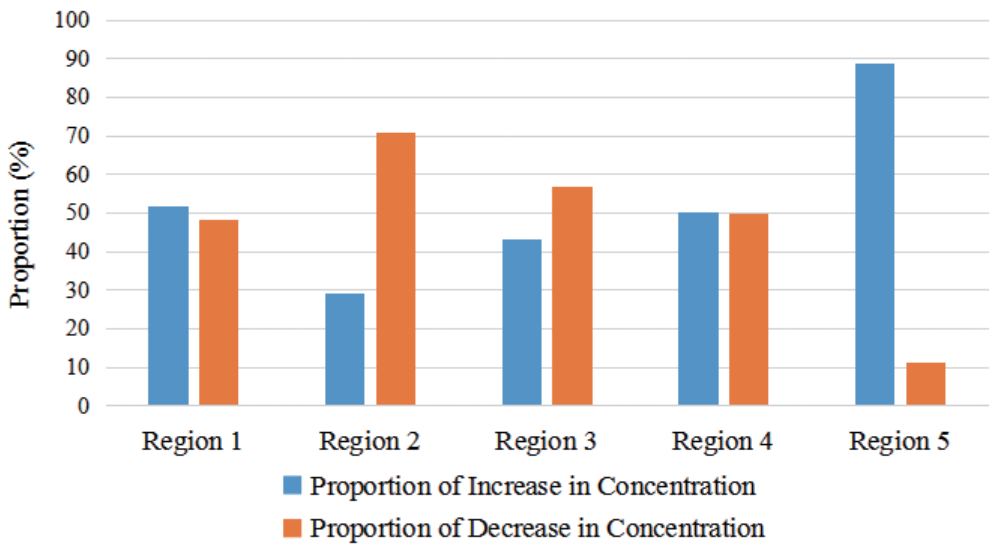

Fig. 6. Statistical results of sea ice concentration changes in the five Antarctic sub-regions from 1998 to 2007 (blue: proportion of sea ice with an increasing trend of concentration; orange: proportion of sea ice with a decreasing trend of concentration).

2008 - 2017: The results of the linear regression of the spatial distribution of the sea-ice concentration from 2008 to 2017 are displayed in Table 5 and Fig. 7. The sea-ice concentration decreased at a rate of $-0.283 \% \mathrm{yr}^{-1}$ for the entire Antarctic region during 2008 to 2017. The sea-ice concentration for both the PO and BS showed increasing trends (the increase for PO was more obvious), whereas the IO, RS, and WS exhibited decreasing trends (the trend for RS being the most obvious). The sea-ice concentration in the RS decreased at a rate of $0.819 \% \mathrm{yr}^{-1}$, and in $87.862 \%$ of the area, a decline in the sea-ice concentration was observed. Compared with 1998 - 2007, only the RS showed the same trend during 2008 - 2017. The changes in the WS were the most significant, and the trend during 2008 - 2017 was opposite to that during 1998 - 2007. Comparison of the changes over the three 10-year intervals revealed that the sea-ice concentration in all sub-regions changed during all intervals. There was a degree of alternation in the changes of the various sub-regions over time, and the changes in the sea-ice concentration were regular, which may be related to ocean circulation and the monsoon. A significant difference between the mean sea-ice concentration and the annual rate of change in the five sub-regions was observed. The change rate of sea-ice concentration in IO, RS, and WS was found to be highly significant $(\mathrm{p}<0.01)$.

\subsection{Spatial Distribution of Antarctic Multi-Year Ice}

\subsubsection{Entire Antarctic Region}

Multi-year ice is more stable than first-year ice, and it is important to obtain a more accurate quantification of the former through the use of data obtained during the minimum SIE. This is because the first-year sea-ice cover has mostly melted at this time, and sea ice that still exists after the melting season is the multi-year ice (Comiso 1990). According to the methods described in section 2, the distribution of Antarctic multi-year ice during 1988 - 2017 was obtained and used to plot Fig. 8: proportions and areas are shown in Table 6.

Figure 8 illustrates that the multi-year ice was mainly distributed in the region adjacent to the continental margin of Antarctica, and that the amount of multi-year ice varied greatly in different sub-regions. The WS had the largest amount of multi-year ice, and the ice that existed for more than 25 years in the 30 -year study period was predominantly distributed in this area. Table 6 shows that during the 30 -year 
Table 5. Sea-ice concentration changes in the five Antarctic sub-regions during 2008 - 2017. IO: Indian Ocean; PO: Pacific Ocean; RS: Ross Sea; BS: Bellingshausen Sea and Amundsen Sea; WS: Weddell Sea.

\begin{tabular}{ccccccc}
\hline & $\begin{array}{c}\text { Mean sea-ice } \\
\text { concentration }\end{array}$ & $\begin{array}{c}\text { Mean rate of } \\
\text { change }\left(\boldsymbol{\%} \mathbf{y r}^{-1}\right)\end{array}$ & $\begin{array}{c}\text { Mean rate of } \\
\text { increase }\left(\boldsymbol{\%} \mathbf{~ y r}^{-1}\right)\end{array}$ & $\begin{array}{c}\text { Mean rate of } \\
\text { decrease }\left(\boldsymbol{\%} \mathbf{~ y r}^{-1}\right)\end{array}$ & $\begin{array}{c}\text { Proportion of } \\
\text { increase }(\boldsymbol{\%})\end{array}$ & $\begin{array}{c}\text { Proportion of } \\
\text { decrease }(\boldsymbol{\%})\end{array}$ \\
\hline IO & 0.419 & $-0.579 * *$ & 0.213 & -0.711 & 14.224 & 85.776 \\
PO & 0.478 & 0.512 & 0.778 & -0.277 & 74.758 & 25.242 \\
RS & 0.555 & $-0.819^{* *}$ & 0.223 & -0.963 & 12.138 & 87.862 \\
BS & 0.512 & 0.064 & 0.766 & -0.727 & 52.984 & 47.016 \\
WS & 0.545 & $-0.169 * *$ & 0.479 & -0.582 & 38.916 & 61.084 \\
Entire Antarctica & 0.513 & $-0.283^{* *}$ & 0.539 & -0.724 & 34.896 & 65.104 \\
\hline
\end{tabular}

Note: $* p<0.05 ; * * p<0.01$.

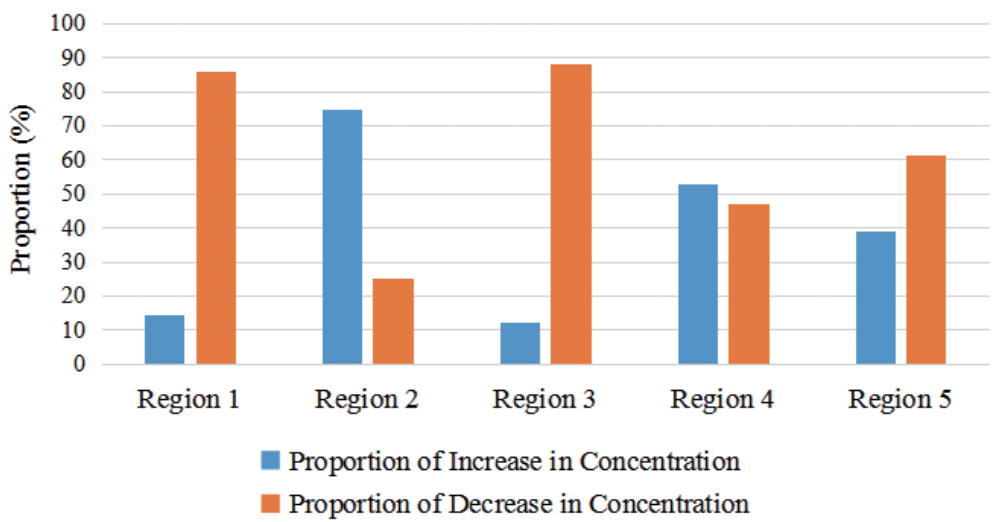

Fig. 7. Statistical results of sea ice concentration changes in the five Antarctic sub-regions from 2008 to 2017 (blue: proportion of sea ice with an increasing trend of concentration; orange: proportion of sea ice with a decreasing trend of concentration).

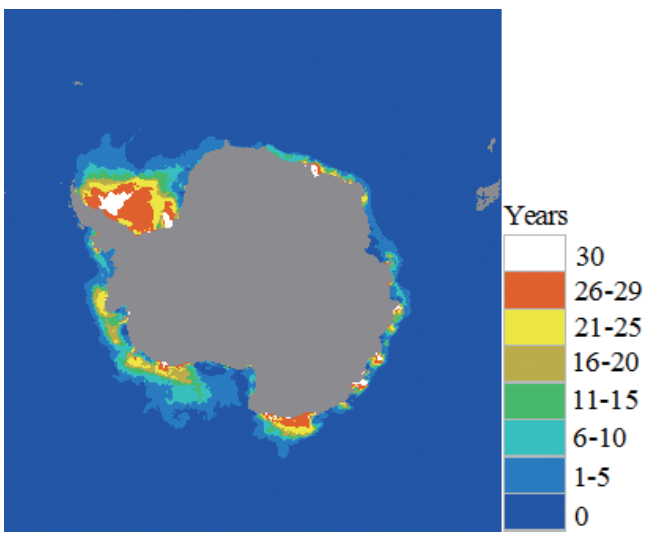

Fig. 8. Temporal and spatial distribution of Antarctic multi-year ice in 1988 - 2017.

Table 6. Multi-year ice areas for different periods during 1988 - 2017.

\begin{tabular}{c|ccccccc}
\hline Time interval (year) & $\mathbf{1 ~ - 5}$ & $\mathbf{6 - 1 0}$ & $\mathbf{1 1} \mathbf{- 1 5}$ & $\mathbf{1 6 - 2 0}$ & $\mathbf{2 1 - 2 5}$ & $\mathbf{2 6}-\mathbf{2 9}$ & $\mathbf{3 0}$ \\
\hline Area $\left(10^{6} \mathrm{~km}^{2}\right)$ & 2.312 & 0.821 & 0.497 & 0.422 & 0.476 & 0.646 & 0.324 \\
Proportion $(\%)$ & 42.06 & 14.92 & 9.04 & 7.67 & 8.67 & 11.75 & 5.89 \\
\hline
\end{tabular}


study period, the largest amount of multi-year ice was that associated with a duration of $<5$ years, which accounted for $42.06 \%$, thus suggesting that Antarctic ice has changed greatly over the years. The amount of multi-year ice that existed for at least 26 years was $17.46 \%$, which indicates that there is a considerable amount of long-term multi-year ice in Antarctica. The 30-year-old multi-year ice cover was estimated to cover approximately $0.324 \times 10^{6} \mathrm{~km}^{2}$ (mainly in the WS), which accounted for $5.89 \%$ of the total multi-year ice.

\subsubsection{Sub-Regions}

We performed statistical analyses for each sub-region (Fig. 1) to compare the distributional differences in the multi-year ice. We divided the multi-year ice area of Antarctica from 1988 to 2017 into 1988 - 1992, 1993 - 1997, 1998 - 2002, 2003 - 2007, 2008 - 2012, and 2013 - 2017, and then divided the multi-year ice area of different periods into six regions according to Fig. 1 to compare the Antarctic multi-year ice (Table 7, Fig. 9). In all of the sub-regions, the 1988 - 1992 multi-year ice accounted for the majority. Multi-year ice that endured the period from 2013 to 2017 was mainly found in the WS and accounted for $54.38 \%$ of the total multi-year ice area in the Antarctic region. The IO had the smallest 2013 - 2017 multi-year ice area $(0.301 \times$ $10^{6} \mathrm{~km}^{2}$ ), accounting for only $8.53 \%$ of the total area.

We divided the 30-year period from 1988 to 2017 into six 5-year successive intervals (Fig. 10) as a means of assessing dynamic changes to the ice area and the distributional differences in each sub-region. Figure 10 illustrates that the area of multi-year ice both in the IO and PO was relatively small, whereas that in the WS was the largest. A significant downward trend was observed in the RS, and the multi-year ice in the BS changed only slightly during the six
5 -year periods. The multi-year ice area in the WS increased obviously over the six 5-year periods, whereas it increased weakly in the IO and decreased in the other sub-regions, especially the RS.

Shu (2019) carried out relevant research on the Antarctic multi-year ice change and regional distribution from 2011 to 2018; the study results showed that in the five sea areas around the Antarctic continent, except the WS, the multi-year ice area presented an increasing trend. In contrast, due to the difference between the study years considered by Shu (2019) and those undertaken in our study, a clear increasing trend of multi-year ice in the WS was observed. Additionally, the temporal trends in the PO and RS were greater than that in the entire Antarctic region, while the trends in the WS, IO, and BS were smaller than that in the entire Antarctic region.

\subsection{Spatial Variation in Antarctic Multi-Year Ice Concentration}

Based on the Antarctic multi-year sea-ice concentration, the mean annual sea-ice concentration was obtained It can be seen from Fig. 11 that the spatial variation in the sea-ice concentration over 30 years varied greatly, but the spatial variation rate was relatively stable when compared with the overall sea-ice concentration (regions indicated in black represent a significance level of $\mathrm{p}<0.05$ ).

The increasing area of the spatial distribution of the multi-year sea-ice concentration over the years was mainly concentrated in the WS, and the decreasing area was largely concentrated in the BS and RS. The temporal trend of the Antarctic multi-year sea-ice concentration was assessed using the data in Table 8. Between 1988 and 2017, the Antarctic multi-year sea-ice concentration exhibited an overall

Table 7. Multi-year ice areas for different sub-regions from 1988 to 2017 (where the area is in $10^{6} \mathrm{~km}^{2}$ ). IO: Indian Ocean; PO: Pacific Ocean; RS: Ross Sea; BS: Bellingshausen Sea and Amundsen Sea; WS: Weddell Sea.

\begin{tabular}{c|c|cccccc}
\hline \multicolumn{2}{c|}{ Region/Time interval } & $\mathbf{1 9 8 8} \mathbf{- 1 9 9 2}$ & $\mathbf{1 9 9 3} \mathbf{- 1 9 9 7}$ & $\mathbf{1 9 9 8} \mathbf{- 2 0 0 2}$ & $\mathbf{2 0 0 3} \mathbf{- 2 0 0 7}$ & $\mathbf{2 0 0 8} \mathbf{- 2 0 1 2}$ & $\mathbf{2 0 1 3} \mathbf{- 2 0 1 7}$ \\
\hline \multirow{2}{*}{ IO } & Area & 0.273 & 0.241 & 0.245 & 0.184 & 0.418 & 0.301 \\
& Proportion & $7.14 \%$ & $7.59 \%$ & $7.58 \%$ & $4.98 \%$ & $12.49 \%$ & $8.53 \%$ \\
\hline \multirow{2}{*}{ PO } & Area & 0.261 & 0.326 & 0.269 & 0.297 & 0.258 & 0.37 \\
& Proportion & $6.84 \%$ & $10.26 \%$ & $8.35 \%$ & $8.01 \%$ & $7.69 \%$ & $10.51 \%$ \\
\hline \multirow{2}{*}{ RS } & Area & 1.115 & 0.746 & 0.99 & 0.969 & 0.716 & 0.586 \\
& Proportion & $29.26 \%$ & $23.45 \%$ & $30.64 \%$ & $26.14 \%$ & $21.39 \%$ & $16.64 \%$ \\
\hline \multirow{2}{*}{ BS } & Area & 0.635 & 0.44875 & 0.537 & 0.536 & 0.449 & 0.351 \\
& Proportion & $16.67 \%$ & $14.07 \%$ & $16.59 \%$ & $14.51 \%$ & $13.40 \%$ & $9.94 \%$ \\
\hline \multirow{2}{*}{ WS } & Area & 1.528 & 1.419 & 1.19 & 1.718 & 1.508 & 1.916 \\
& Proportion & $40.09 \%$ & $44.63 \%$ & $36.84 \%$ & $46.36 \%$ & $45.03 \%$ & $54.38 \%$ \\
\hline \multirow{2}{*}{ Antarctic } & Area & 3.812 & 3.181 & 3.231 & 3.704 & 3.349 & 3.524 \\
& Proportion & $100 \%$ & $100 \%$ & $100 \%$ & $100 \%$ & $100 \%$ & $100 \%$ \\
\hline
\end{tabular}




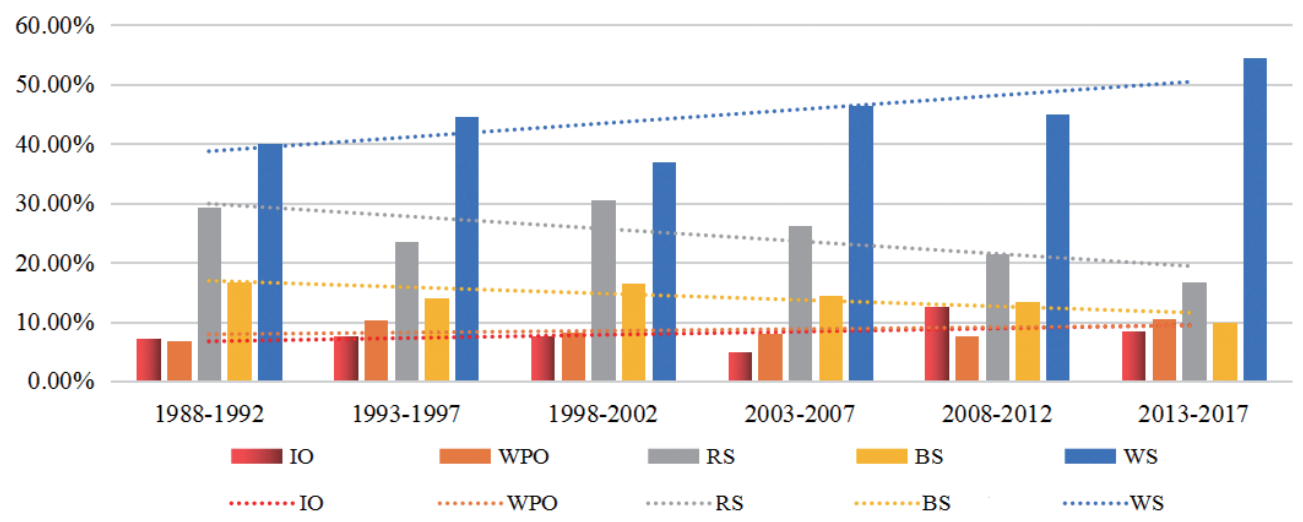

Fig. 9. Percentage of Antarctic multi-year ice sea ice in each sub-region during six 5-year periods from 1988 to 2017 (six 5-year intervals: 1988 1992, 1993 - 1997, 1998 - 2002, 2003 - 2007, 2008 - 2012, 2013 - 2017; WPO: western Pacific Ocean; RS: Ross Sea; WS: Weddell Sea; IO: Indian Ocean; BS: Bellingshausen Sea and Amundsen Sea).

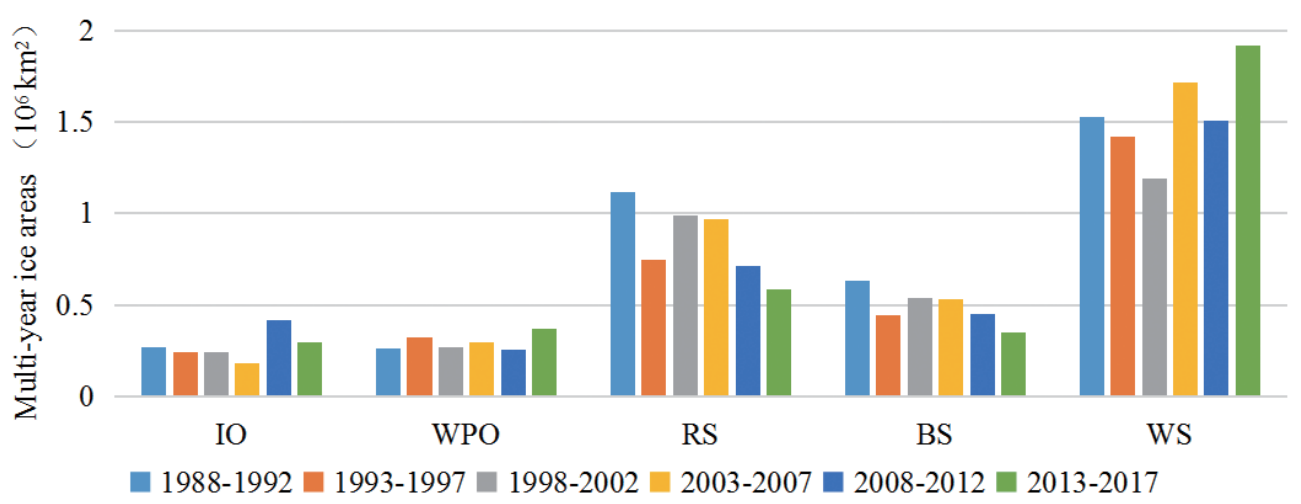

Fig. 10. Variation and distribution of multi-year ice areas in each sub-region during six 5-year periods from 1988 - 2017 (six 5-year intervals: 1988 - 1992, 1993 - 1997, 1998 - 2002, 2003 - 2007, 2008 - 2012, 2013 - 2017).

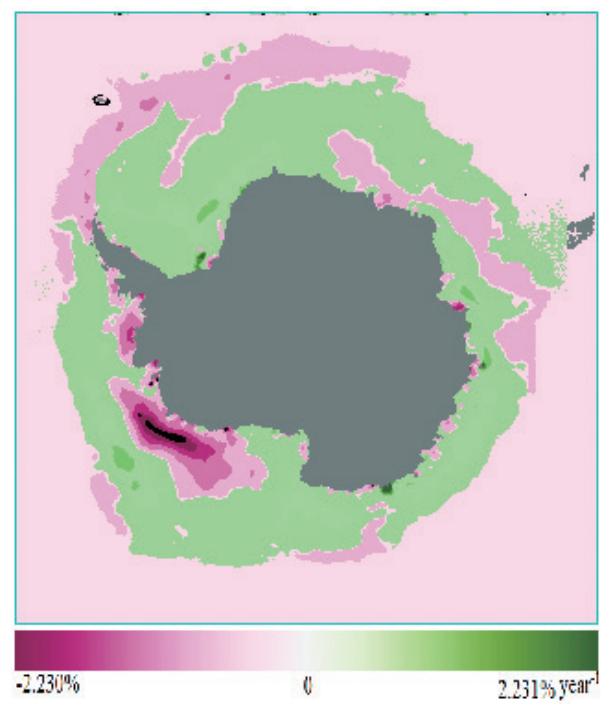

Fig. 11. Spatial distribution of the Antarctic multi-year concentration linear trend. regions indicated in black represent a significance level of $\mathrm{p}<$ 0.05 . 
Table 8. Spatial and temporal variations of the sea-ice concentration in the five sub-regions of the Antarctic. IO: Indian Ocean; PO: Pacific Ocean; RS: Ross Sea; BS: Bellingshausen Sea and Amundsen Sea; WS: Weddell Sea.

\begin{tabular}{c|ccccc}
\hline Region & $\begin{array}{c}\text { Mean rate of } \\
\text { change }\left(\mathbf{\%} \mathbf{y r}^{-1}\right)\end{array}$ & $\begin{array}{c}\text { Extent of increase } \\
\left(\mathbf{1 0}^{\mathbf{6}} \mathbf{k m}^{\mathbf{2}}\right)\end{array}$ & $\begin{array}{c}\text { Extent of decrease } \\
\left(\mathbf{1 0}^{\mathbf{6}} \mathbf{k m}^{\mathbf{2}}\right)\end{array}$ & $\begin{array}{c}\text { Proportion of } \\
\text { increase } \mathbf{( \% )}\end{array}$ & $\begin{array}{c}\text { Proportion of } \\
\text { decrease (\%) }\end{array}$ \\
\hline Antarctic & 0.136 & 3.259 & 2.139 & 100 & 100 \\
IO & 0.084 & 0.291 & 0.152 & 8.95 & 7.32 \\
PO & 0.055 & 0.271 & 0.213 & 8.34 & 9.96 \\
RS & $-0.2^{*}$ & 0.619 & 1.005 & 18.99 & 47.15 \\
BS & $-0.438^{*}$ & 0.141 & 0.598 & 4.34 & 28.12 \\
WS & 0.623 & 1.935 & 0.157 & 59.38 & 7.45 \\
\hline
\end{tabular}

Note: $* p<0.05 ; * * p<0.01$.

increasing trend. In the entire Antarctic region, the pixel proportion of the multi-year sea-ice concentration increased by $66.67 \%$, and the maximum growth rate was $2.231 \% \mathrm{yr}^{-1}$. The proportion of pixels with a decreasing multi-year seaice concentration was $33.33 \%$, and the maximum negative growth rate was $-2.23 \% \mathrm{yr}^{-1}$. The rate of change of the multiyear sea-ice concentration over the entire Antarctic region presented an increasing trend of $0.136 \% \mathrm{yr}^{-1}$. Within this, the RS and BS showed significant downward trends; the most obvious decrease in the BS was $-0.438 \% \mathrm{yr}^{-1}$, which accounted for $47.15 \%$ of the total reduction in the area of Antarctica sea-ice. Of the five sub-regions, the rate of change of the sea-ice concentration in WS increased most obviously $\left(0.623 \% \mathrm{yr}^{-1}\right)$ and accounted for $59.38 \%$ of the total growth area of the entire Antarctic sea ice. The IO and PO also showed increasing trends; however, but the rates of change were smaller than that of the entire Antarctic region. The change rate of sea-ice concentration in RS and BS passed was significance at $\mathrm{p}<0.05$.

The spatial distribution characteristics of the multiyear sea-ice concentration are obvious; a decreasing trend was observed for the RS, Berengskein Sea, and Amundsen Sea, whereas an increasing trend was observed for the other sea areas (the changes noted for the Weddell Sea area were the most obvious). On the whole, the sea areas of the Antarctic sea ice are remarkably different. The sea-ice decrease in the southwest pole is more serious, which has a certain relationship with the intrinsic instability in the nature of the southwest pole (Bamber et al. 2009; Xu 2014), which in turn, is influenced by various factors such as atmospheric climate, iceberg ice shelf, atmospheric pressure and precipitation (Curran et al. 2003). Current research shows that the causes of the Antarctic sea ice change are as follows. Firstly, the ice shelf on the edge of Antarctic ice sheet has broken, collapsed, and melted in recent years due to climate warming. The fresh water from melting is beneficial to the formation of the Antarctic sea ice. Secondly, global warming increases the salinity of the sea surface, which is also conducive to the formation of new ice. Further, the amount of snowfall has increased, and thus, the reflectivity of the sea ice covered by snow is higher, leading to a reduction in the melting of the sea ice. Thirdly, the ozone hole over Antarctica enhances the offshore wind speed on the surface, resulting in an increase in the amount of sea ice floating off the coast of the continent, which will lead to the increase of sea-ice range (Curran et al. 2003; Qin et al. 2017).

\section{CONCLUSION}

Based on the sea-ice concentration data from 1988 to 2017, the spatial distribution and variation in Antarctic sea ice over the past 30 years were studied and analyzed using two sea-ice parameters: sea-ice concentration and multiyear sea ice. The temporal variations in these parameters were studied through the analysis of the 30-year dataset as a means of comparing the changes and trends in the Antarctic sea ice. Spatially, the entire Antarctic region was divided into five sub-regions: the IO, PO, RS, BS, and WS. With regard to the spatial variation in the rate of change of the seaice concentration over time, the conclusions are as follows:

(1) From 1988 to 2017, the mean sea-ice concentration for the entire Antarctic region was 0.506. The SIA with a concentration of $0.6-0.7$ was the largest, accounting for $20.673 \%$ of the total Antarctic sea ice. The mean sea-ice concentration was the highest in the RS (0.552) and lowest in the IO (0.412). The temporal trends in the sea-ice concentration over the 30-year period differed between the sub-regions; whereby the decrease of the sea-ice concentration in the PO was the most obvious, and the increase in the WS was the most significant.

(2) Linear regression was applied to annual average sea-ice concentration data. The spatial variation in the sea-ice concentration over the entire Antarctic region was analyzed, and the spatial distribution of the three 10-year trends in the mean sea-ice concentration was obtained. The results indicated clear spatial differences in the linear trends. The sea-ice concentration in the IO and BS both increased and decreased alternately over the three 
decades. The sea-ice concentration in the PO and RS for the period 1988 - 1997 was positive, but exhibited a downward trend during the latter two 10-year intervals. The sea-ice concentration in the WS increased during 1988 - 1997 and 1998 - 2007, but decreased considerably during 2008 - 2017.

(3) Statistical analysis of the Antarctic multi-year sea-ice from 1988 to 2017 demonstrated that multi-year ice was mainly distributed in the region adjacent to the continental margin of Antarctica, and that the amount of multiyear ice varied greatly in different sub-regions. The duration of multi-year ice was divided into six 5-year periods. The amount of multi-year ice in the WS was found to be the largest, and the ice that has existed for more than 25 years during the entire 30 -year period was mainly distributed in the WS. The results showed that during the 30-year study period, the largest proportion of multi-year ice existed for 1 - 5 years. The multi-year ice areas of the IO and WS exhibited continuous growth trends over the 30 -year period. The RS multi-year ice data displayed a significant downward trend, and the changes in the multi-year ice in the PO were small.

(4) Based on Antarctic multi-year sea-ice concentration, the mean annual sea-ice concentration for the entire Antarctic region was obtained. The areas where the multi-year ice concentration increased (decreased) were mainly concentrated in the WS (BS and RS). The RS and BS presented significant downward trends. The largest decreasing trend for the BS data was $-0.438 \% \mathrm{yr}^{-1}$, which accounted for $47.15 \%$ of the total reduction in the area of Antarctic sea ice. The strongest increasing trend was observed for the WS $\left(0.623 \% \mathrm{yr}^{-1}\right)$, whereby the growth accounted for an estimated $59.38 \%$ of the total increase in the Antarctic SIA. The IO and PO also showed increasing trends, although the rates of change were smaller than that of the entire Antarctic region.

Acknowledgements This research was supported by the Key Laboratory of Ocean Circulation and Waves, Institute of Oceanography, Chinese Academy of Sciences (grant no. KLOCW1805); Open fund project of National-Local Joint Engineering Laboratory on Digital Preservation and Innovative Technologies for the Culture of Traditional Villages and Towns (grant no. CTCZ18K07); Open Research Fund of the Key Laboratory of Digital Earth Science, Institute of Remote Sensing and Digital Earth, Chinese Academy of Sciences (grant no. 2018LDE005). We thank the Chief Editor of the Journal and the anonymous reviewers for their time, effort, and suggestions, which significantly improved the manuscript.

\section{REFERENCES}

Bamber, J. L., R. E. M. Riva, B. L. A. Vermeersen, and
A. M. LeBrocq, 2009: Reassessment of the Potential Sea-Level Rise from a Collapse of the West Antarctic Ice Sheet. Science, 324, 901-903, doi: 10.1126/science.1169335. [Link]

Bi, H., Y. Liang, Y. Wang, X. Liang, Z. Zhang, T. Du, Q. Yu, J. Huang, M. Kong, and H. Huang, 2020: Arctic multiyear sea ice variability observed from satellites: A review. J. Oceanol. Limnol., 38, 962-984, doi: 10.1007/s00343-020-0093-7. [Link]

Cavalieri, D. J. and C. L. Parkinson, 2008: Antarctic sea ice variability and trends, 1979-2006. J. Geophys. Res., 113, C07004, doi: 10.1029/2007jc004564. [Link]

Cavalieri, D. J. and C. L. Parkinson, 2012: Arctic sea ice variability and trends, 1979-2010. The Cryosphere, 6, 881-889, doi: 10.5194/tc-6-881-2012. [Link]

Cavalieri, D. J., C. L. Parkinson, and K. Y. Vinnikov, 2003: 30-year satellite record reveals contrasting Arctic and Antarctic decadal sea ice variability. Geophys. Res. Lett., 30, doi: 10.1029/2003gl018031. [Link]

Comiso, J. C., 1990: Arctic multiyear ice classification and summer ice cover using passive microwave satellite data. J. Geophys. Res., 95, 13411-13422, doi: 10.1029/ jc095ic08p13411. [Link]

Comiso, J. C., 2000: Variability and Trends in Antarctic Surface Temperatures from In Situ and Satellite Infrared Measurements. J. Climate, 13, 1674-1696, doi: 10.1175/1520-0442(2000)013<1674:VATIAS > 2.0. $\mathrm{CO} ; 2$. [Link]

Cook, A. J., A. J. Fox, D. G. Vaughan, and J. G. Ferrigno, 2005: Retreating Glacier Fronts on the Antarctic Peninsula over the Past Half-Century. Science, 308, 541544, doi: 10.1126/science.1104235. [Link]

Curran, M. A. J., T. D. Van Ommen, V. I. Morgan, K. L. Phillips, and A. S. Palmer, 2003: Ice core evidence for Antarctic sea ice decline since the 1950s. Science, 302, 1203-1206, doi: 10.1126/science.1087888. [Link]

Heinrichs, J. F., D. J. Cavalieri, and T. Markus, 2006: Assessment of the AMSR-E Sea Ice-Concentration product at the ice edge using RADARSAT-1 and MODIS imagery. IEEE Trans. Geosci. Remote Sensing, 44, 3070-3080, doi: 10.1109/tgrs.2006.880622. [Link]

Lange, B. A., J. F. Beckers, J. A. Casey, and C. Haas, 2019: Airborne observations of summer thinning of multiyear sea ice originating from the Lincoln Sea. J. Geophys. Res., 124, 243-266, doi: 10.1029/2018JC014383. [Link]

Liu, J., J. A. Curry, and D. G. Martinson, 2004: Interpretation of recent Antarctic sea ice variability. Geophys. Res. Lett., 31, doi: 10.1029/2003gl018732. [Link]

Liu, Y., 2016: Antarctic and Arctic Sea Ice Concentration Estimation and Sea Ice Extent Time Series Analysis. Master Thesis, Wuhan University.

Maslanik, J. and J. Stroeve, 2016: DMSP SSM/I-SSMIS Daily Polar Gridded Brightness Temperatures. 
National Snow and Ice Data Center, Boulder, CO. Available at http://nsidc.org/data/nsidc-0001/. (Accessed on 28 March 2016)

Massom, R. A. and S. E. Stammerjohn, 2010: Antarctic sea ice change and variability - Physical and ecological implications. Polar Sci., 4, 149-186, doi: 10.1016/j. polar.2010.05.001. [Link]

Parkinson, C. L., 2004: Southern Ocean sea ice and its wider linkages: Insights revealed from models and observations. Antarct. Sci., 16, 387-400, doi: 10.1017/ s0954102004002214. [Link]

Parkinson, C. L. and D. J. Cavalieri, 2012: Antarctic sea ice variability and trends, 1979-2010. The Cryosphere, 6, 871-880, doi: 10.5194/tc-6-871-2012. [Link]

Parkinson, C. L., D. J. Cavalieri, P. Gloersen, H. J. Zwally, and J. C. Comiso, 1999: Arctic sea ice extents, areas, and trends, 1978-1996. J. Geophys. Res., 104, $20837-$ 20856, doi: 10.1029/1999jc900082. [Link]

Qin, D., T. Yao, and Y. Ding, 2017: Introduction to Cryosphere Science, Science Press, Beijing.

Screen, J. A., T. J. Bracegirdle, and I. Simmonds, 2018: Polar Climate Change as Manifest in Atmospheric Circulation. Curr. Clim. Chang. Rep., 4, 383-395, doi: 10.1007/s40641-018-0111-4. [Link]

Shen, X., C. Ke, and J. Zhang, 2017: Analysis on spatiotemporal variations of Antarctic sea ice during 20022011. Chinese Polar Expedition Encyclopedia, 29, 163-171.

Shu, S., 2019: Analysis of Antarctic sea ice variations from 2011 to 2018. Master Thesis, Nanjing University.

Simmonds, I., 2015: Comparing and contrasting the behaviour of arctic and antarctic sea ice over the 35 year period 1979-2013. Ann. Glaciol., 56, 18-28, doi: 10.3189/2015aog69a909. [Link]

Simmonds, I. and T. H. Jacka, 1995: Relationships between the interannual variability of antarctic sea ice and the southern oscillation. J. Climate, 8, 637-647, doi: 10.1175/1520-0442(1995)008<0637:RBTIVO>2.0. $\mathrm{CO} ; 2$. [Link]

Swift, C. T. and D. J. Cavalieri, 1985: Passive microwave remote sensing for sea ice research. Eos, Trans. AGU, 66, 1210-1212, doi: 10.1029/eo066i049p01210. [Link] Turner, J., J. S. Hosking, G. J. Marshall, T. Phillips, and T. J. Bracegirdle, 2016: Antarctic sea ice increase consistent with intrinsic variability of the Amundsen Sea Low. Clim. Dyn., 46, 2391-2402, doi: 10.1007/s00382015-2708-9. [Link]

White, W. B. and I. Simmonds, 2006: Sea surface temperature-induced cyclogenesis in the Antarctic circumpolar wave. J. Geophys. Res., 111, C08011, doi: 10.1029/2004jc002395. [Link]

White, W. B., P. Gloersen, and I. Simmonds, 2004: Tropospheric Response in the Antarctic Circumpolar Wave along the Sea Ice Edge around Antarctica. J. Climate, 17, 2765-2779, doi: 10.1175/1520-0442(2004)017<2765:TRITAC >2.0. $\mathrm{CO} ; 2$. [Link]

Xu, D., 2014: Study on the relationship between Arctic sea ice change and Northern Hemisphere sea temperature. The 31st Annual Meeting of China Meteorological Society S6 Atmospheric Composition and Weather, Climate Change.

Zwally, H. J., J. C. Comiso, C. L. Parkinson, D. J. Cavalieri, and P. Gloersen, 2002: Variability of Antarctic sea ice 1979-1998. J. Geophys. Res., 107, 9-1-9-19, doi: 10.1029/2000jc000733. [Link] 